Trinity University

Digital Commons @ Trinity

Chemistry Faculty Research

Chemistry Department

9-5-2005

\title{
Origin of Enantioselection in Chiral Alcohol Oxidation Catalyzed by $\mathrm{Pd}[(-)$-sparteine $] \mathrm{Cl} 2$
}

\author{
J.A. Mueller \\ Anne Cowell \\ Trinity University \\ Bert D. Chandler \\ Trinity University, bchandle@trinity.edu \\ M. S. Sigman
}

Follow this and additional works at: https://digitalcommons.trinity.edu/chem_faculty

Part of the Chemistry Commons

\section{Repository Citation}

Mueller, J. A., Cowell, A., Chandler, B. D., \& Sigman, M. S. (2005). Origin of enantioselection in chiral alcohol oxidation catalyzed by $\operatorname{pd}[(-)$-sparteine $] \mathrm{Cl}_{2}$. Journal of the American Chemical Society, 127(42), 14817-14824.

This Article is brought to you for free and open access by the Chemistry Department at Digital Commons @ Trinity. It has been accepted for inclusion in Chemistry Faculty Research by an authorized administrator of Digital Commons @ Trinity. For more information, please contact jcostanz@trinity.edu. 


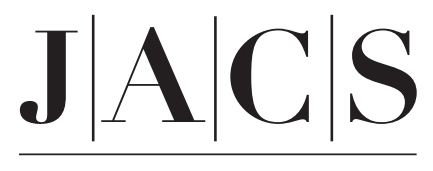

A R T I C L E S

Published on Web 09/29/2005

\title{
Origin of Enantioselection in Chiral Alcohol Oxidation Catalyzed by $\mathrm{Pd}[(-)$-sparteine $] \mathrm{Cl}_{2}$
}

\author{
Jaime A. Mueller, ${ }^{\dagger}$ Anne Cowell, ${ }^{+}$Bert D. Chandler, ${ }^{*} \neq$ and Matthew S. Sigman ${ }^{*} \dagger$ \\ Contribution from the Departments of Chemistry, University of Utah, 315 South 1400 East, \\ Salt Lake City, Utah 84112, and Trinity University, One Trinity Place, \\ San Antonio, Texas 78212-7200 \\ Received May 16, 2005; E-mail: bert.chandler@trinity.edu; sigman@chem.utah.edu
}

\begin{abstract}
A kinetic investigation into the origin of enantioselectivity for the $\mathrm{Pd}[(-)$-sparteine $] \mathrm{Cl}_{2}$-catalyzed aerobic oxidative kinetic resolution (OKR) is reported. A mechanism to account for a newly discovered chloride dissociation from $\mathrm{Pd}\left[(-)\right.$-sparteine $\mathrm{Cl}_{2}$ prior to alcohol binding is proposed. The mechanism includes (1) chloride dissociation from $\mathrm{Pd}[(-)$-sparteine $] \mathrm{Cl}_{2}$ to form cationic $\mathrm{Pd}(-)$-sparteine $] \mathrm{Cl},(2)$ alcohol binding, (3) deprotonation of $\mathrm{Pd}$-bound alcohol to form a Pd-alkoxide, and (4) $\beta$-hydride elimination of $\mathrm{Pd}$-alkoxide to form ketone product and a $\mathrm{Pd}$-hydride. Utilizing the addition of $(-)$-sparteine $\mathrm{HCl}$ to control the $\left[\mathrm{Cl}^{-}\right]$ and $\left[\mathrm{H}^{+}\right]$and the resulting derived rate law, the key microscopic kinetic and thermodynamic constants were extracted for each enantiomer of sec-phenethyl alcohol. These constants allow for the successful simulation of the oxidation rate in the presence of exogenous $(-)$-sparteine $\mathrm{HCl}$. A rate law for oxidation of the racemic alcohol was derived that allows for the successful prediction of the experimentally measured $k_{\text {rel }}$ values when using the extracted constants. Besides a factor of 10 difference between the relative rates of $\beta$-hydride elimination for the enantiomers, the main enhancement in enantiodetermination results from a concentration effect of $(-)$-sparteine $\mathrm{HCl}$ and the relative rates of reprotonation of the diastereomeric Pd-alkoxides.
\end{abstract}

\section{Introduction}

The field of asymmetric catalysis has grown tremendously as a means to access enantiomerically enriched building blocks. Accessing nonracemic alcohols, which are important as starting materials, by asymmetric catalysis has garnered significant attention from the synthetic community. A key strategy to accessing highly enantiomerically enriched alcohols has been kinetic resolution of racemic alcohols. ${ }^{1-6}$ The nonenzymatic kinetic resolution of secondary alcohols has been accomplished using a variety of methods including epoxidation, ${ }^{7-9}$ acylation with nucleophilic catalysts, ${ }^{10-15}$ and oxidation. ${ }^{16-20}$

Considering that the maximum theoretical yield of a kinetic resolution is $50 \%$, useful methods require at least a 20 -fold

\section{* Corresponding author.}

Department of Chemistry, University of Utah.

$\doteqdot$ Department of Chemistry, Trinity University.

(1) For a review on kinetic resolutions using nonenzymatic catalysts, see: Robinson, D. E. J. E.; Bull, S. D. Tetrahedron: Asymmetry 2003, 14, 14071446.

(2) Turner Nicholas, J. Curr. Opin. Chem. Biol 2004, 8, 114-119.

(3) For a review on kinetic resolutions of secondary alcohols, see: Somfai, P. In Organic Synthesis Highlights IV; Schmalz, H.-G., Ed.; Wiley-VCH: Weinheim, Germany, 2000; pp 175-181.

(4) Somfai, P. Angew. Chem., Int. Ed. 1998, 36, 22731-2733.

(5) For a review on metal-catalyzed kinetic resolutions, see: Hoveyda, A. H.; Didiuk, M. T. Curr. Org. Chem. 1998, 2, 489-526.

(6) Cook, G. R. Curr. Org. Chem. 2000, 4, 869-885.

(7) Martin, V. S.; Woodard, S. S.; Katsuki, T.; Yamada, Y.; Ikeda, M.; Sharpless, K. B. J. Am. Chem. Soc. 1981, 103, 6237-6240.

(8) Adam, W.; Humpf, H.-U.; Roschmann, K. J.; Saha-Moeller, C. R. J. Org. Chem. 2001, 66, 5796-5800.

(9) Yang, D.; Jiao, G.-S.; Yip, Y.-C.; Lai, T.-H.; Wong, M.-K. J. Org. Chem. 2001, 66, 4619-4624

(10) Yamada, S.; Misono, T.; Iwai, Y. Tetrahedron Lett. 2005, 46, 2239-2242.

(11) Santi, C.; Tiecco, M.; Testaferri, L.; Tomassini, C.; Marini, F.; Bagnoli, L.; Temperini, A. Phosphorus, Sulfur, Silicon Relat. Elem. 2005, 180, $1071-1075$.

10.1021/ja053195p CCC: $\$ 30.25 \odot 2005$ American Chemical Society difference in the relative reaction rates of the respective enantiomers to provide reasonable yields of enantiomerically enriched materials. ${ }^{21}$ Many kinetic resolutions do not achieve this goal. In 2001, we reported the Pd-catalyzed aerobic oxidative kinetic resolution (OKR) of secondary alcohols using $(-)$-sparteine which, for selected substrates, gives $k_{\text {rel }}$ values of $>20 . .^{22,23} \mathrm{We}$ sought to investigate the origin of enantioselectivity in this catalyst system in order to expand the system's utility, ${ }^{24,25}$ potentially improve catalyst design, and provide a deeper understanding for asymmetric catalyst design in general.

(12) For a recent review of kinetic resolutions using nucleophilic catalysts, see: Jarvo, E. R.; Miller, S. J. In Comprehensive Asymmetric Catalysis, Supplement; Jacobsen, E. N., Pfaltz, A., Yamamoto, H., Eds.; Springer: Berlin, Germany, 2004; pp 189-206.

(13) Suzuki, Y.; Yamauchi, K.; Muramatsu, K.; Sato, M. Chem. Commun. 2004, 2770-2771.

(14) Vedejs, E.; Daugulis, O. J. Am. Chem. Soc 2003, 125, 4166-4173.

(15) Dalaigh, C. O.; Hynes, S. J.; Maher, D. J.; Connon, S. J. Org. Biomol. Chem. 2005, 3, 981-984

(16) Kinetic resolution via alcohol oxidation was covered in a review on selective alcohol oxidations, see: Arterburn, J. B. Tetrahedron 2001, 57, 97659788 .

(17) For a recent example of aerobic oxidative kinetic resolution of alcohols, see: Radosevich, A. T.; Musich, C.; Toste, F. D. J. Am. Chem. Soc. 2005, 127, 1090-1091.

(18) Irie, R.; Katsuki, T. Chem. Rec. 2004, 4, 96-109.

(19) Sun, W.; Wang, H.; Xia, C.; Li, J.; Zhao, P. Angew. Chem., Int. Ed. 2003 $42,1042-1044$.

(20) Nishibayashi, Y.; Yamauchi, A.; Onodera, G.; Uemura, S. J. Org. Chem. 2003, 68, 5875-5880.

(21) For an excellent discussion of the practical aspects of kinetic resolutions, see: Keith, J. M.; Larrow, J. F.; Jacobsen, E. N. Adv. Synth. Catal. 2001 $343,5-26$

(22) Jensen, D. R.; Pugsley, J. S.; Sigman, M. S. J. Am. Chem. Soc. 2001, 123, 7475-7476.

(23) (a) A closely related $\mathrm{Pd} /(-)$-sparteine system for aerobic oxidative kinetic resolution was reported simultaneously and independently, see: Ferreira, E. M.; Stoltz, B. M. J. Am. Chem. Soc. 2001, 123, 7725-7726. (b) Also see: Stoltz, B. M. Chem. Lett. 2004, 33, 362-367. 
Scheme 1. Original Proposed Mechanism for Pd-Catalyzed Oxidation of Alcohols

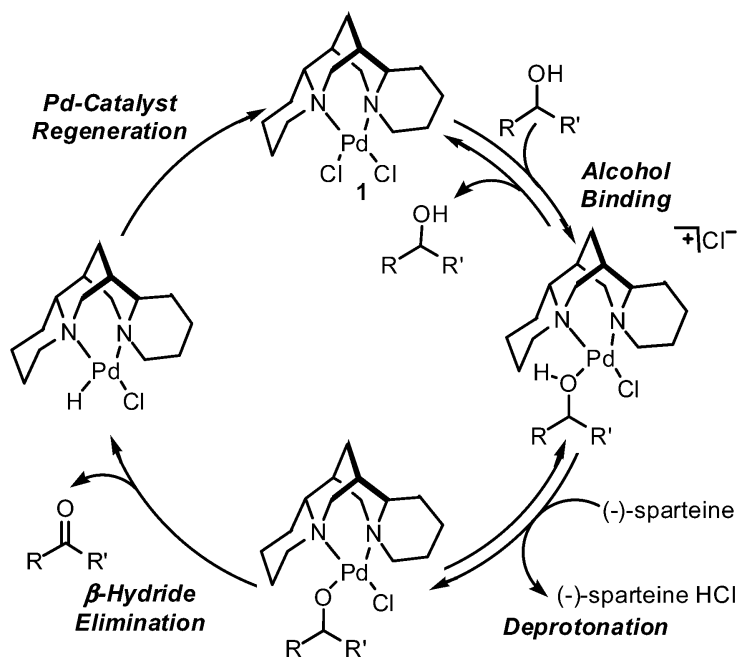

Our previous kinetic investigations into this system determined several of the mechanistic details and offered our first insights into the origin of enantioselection. ${ }^{26,27}$ Further efforts have focused on developing a more precise kinetic and enantioselective model for chiral alcohol oxidation. Of note, a structural model of enantioselection based on isolated $\mathrm{Pd}-$ alkoxides that cannot undergo $\beta$-hydride elimination has been proposed by Trend and Stoltz. ${ }^{28}$ A key component of this structural model invokes diastereoselective chloride ion substitution as an important influence on asymmetric induction. Theoretical approaches have also been implemented to elucidate the origin of enantioselectivity. ${ }^{29}$ After defining the most energetically favored pathway, Nielsen and co-workers compared $k_{\text {rel }}$ values generated from transition-state calculations of $\beta$-hydride elimination to experimental $k_{\text {rel }}$ values. They concluded that the enantioselectivity of Pd-catalyzed alcohol OKR is primarily due to kinetic $\beta$-hydride elimination and is greatly influenced by the nature of the Pd-catalyst counterion. A limitation of their study is that deprotonation/reprotonation could not be addressed due to the large number of atoms in the relevant structures.

As a complement to the structural and theoretical studies, we report herein a kinetic model of the enantiodifferentiation between chiral alcohols during Pd-catalyzed aerobic oxidation using (-)-sparteine. This model allows for the extraction of thermodynamic and kinetic constants for each enantiomer of sec-phenethyl alcohol and successfully predicts the experimental $k_{\text {rel }}$ values under synthetically relevant reaction conditions.

\section{Background}

Previous kinetic studies support a mechanism involving alcohol binding by $\mathrm{Pd}[(-)$-sparteine $] \mathrm{Cl}_{2}$ (1), followed by deprotonation of the Pd-bound alcohol to form a Pd alkoxide (Scheme 1). The Pd-alkoxide species can undergo $\beta$-hydride

(24) Caspi, D. D.; Ebner, D. C.; Bagdanoff, J. T.; Stoltz, B. M. Adv. Synth. Catal. 2004, 346, 185-189.

(25) Ali, I. S.; Sudalai, A. Tetrahedron Lett. 2002, 43, 5435-5436.

(26) Mueller, J. A.; Jensen, D. R.; Sigman, M. S. J. Am. Chem. Soc. 2002, 124 8202-8203.

(27) Mueller, J. A.; Sigman, M. S. J. Am. Chem. Soc. 2003, 125, 7005-7013.

(28) Trend, R. M.; Stoltz, B. M. J. Am. Chem. Soc. 2004, 126, 4482-4483.

(29) Nielsen, R. J.; Keith, J. M.; Stoltz, B. M.; Goddard, W. A., III. J. Am. Chem. Soc. 2004, 126, 7967-7974.
Table 1. Summary of Kinetic Studies of Pd-Catalyzed Oxidative Kinetic Resolution of Secondary Alcohols

\begin{tabular}{|c|c|c|}
\hline \multicolumn{3}{|c|}{$\begin{array}{c}1 \text { mol\% Pd[(-)-sparteine }] \mathrm{Cl}_{2} \\
4-50 \text { mol\% }(-) \text {-sparteine } \\
\text { DCE, balloon } \mathrm{O}_{2}, 60{ }^{\circ} \mathrm{C} \\
\end{array}$} \\
\hline parameter & $\begin{array}{c}50 \mathrm{~mol} \% \\
{[(-)-\text { sparteine }]}\end{array}$ & $\begin{array}{c}4 \mathrm{~mol} \% \\
{[(-) \text {-sparteine] }}\end{array}$ \\
\hline$\left[\mathrm{Pd}(-)\right.$-sparteine $\left.\mathrm{Cl}_{2}\right]$ & first order & first order \\
\hline [sec-phenethyl alcohol] & first order & first order \\
\hline $\begin{array}{l}{[(-) \text {-sparteine }]} \\
{[(-) \text {-sparteine } \mathrm{HCl}]}\end{array}$ & $\begin{array}{l}\text { saturated } \\
\text { inhihition }\end{array}$ & first order \\
\hline $\begin{array}{l}{[(-) \text {-sparteine } \mathrm{HCl}]} \\
\mathrm{KIE}\end{array}$ & $\begin{array}{l}\text { inhibition } \\
1.31 \pm 0.04\end{array}$ & $1.04 \pm 0.06$ \\
\hline Hammett correlation & $\rho=1.41 \pm 0.15$ & no correlation \\
\hline intrinsic $k_{\text {rel }}$ value & & 6.1 \\
\hline racemate $k_{\text {rel }}$ value & $25 \pm 5.0$ & $7.6 \pm 2.0$ \\
\hline
\end{tabular}

elimination to liberate the ketone product and form a $\mathrm{Pd}-$ hydride, followed by fast regeneration of $\mathbf{1}$ using $\mathrm{O}_{2}$. Kinetic experiments revealed an intriguing dependence on exogenous [(-)-sparteine]: (1) It acts as a Brønsted base to deprotonate the $\mathrm{Pd}$-bound alcohol, forming (-)-sparteine $\mathrm{HCl}$ as a transient intermediate. (2) It induces a saturation event as it increases from 4 to $50 \mathrm{~mol} \%$. This implies a change in rate-determining steps at different $[(-)$-sparteine $]$. At low [(-)-sparteine], no observed Hammett correlation and a unity KIE value for $\mathrm{C}-\mathrm{H}(\mathrm{D})$ in sec-phenethyl alcohol suggests that alcohol deprotonation is rate determining. At high [(-)-sparteine], a KIE value for $\mathrm{C}-\mathrm{H}(\mathrm{D})$ in sec-phenethyl alcohol of $1.3 \pm 0.04$ and a $\rho$-value of $-1.4 \pm 0.5$ support a shift from deprotonation to $\beta$-hydride elimination as the rate-limiting step.

The OKR enantioselectivity for secondary alcohols is substantially influenced by [(-)-sparteine]. At $4 \mathrm{~mol} \%$ (-)sparteine, the intrinsic $k_{\text {rel }}$, calculated by comparing the measured single enantiomer oxidation rates, is similar to the racemate $k_{\text {rel }}$ measured during OKR experiments (Table 1). However, at 50 mol \% (-)-sparteine, the racemate $k_{\text {rel }}$ is more than double the intrinsic $k_{\text {rel }}$ of 11. Several mechanistic factors may influence enantiodifferentiation, including the role of chloride ion and the presence of (-)-sparteine $\mathrm{HCl}$, a large, chiral Brønsted acid. Enantiodifferentiation may also be affected by thermodynamic differences between the diastereomeric alkoxide stabilities, relative rates of $\beta$-hydride elimination, and competition between alcohol enantiomers for a single chiral catalyst. While the change in rate-limiting step at low [(-)-sparteine] to deprotonation is interesting, the highest selectivities were garnered at high [(-)sparteine] conditions. Therefore, the addition of several key experiments and the reconsideration of previous results have been utilized to elucidate the thermodynamic and/or kinetic factors that control asymmetric induction at high $[(-)$-sparteine $]$.

\section{Results}

Single Enantiomer Experiments. Earlier studies demonstrated that exogenous (-)-sparteine $\mathrm{HCl}$ inhibits the rate of alcohol oxidation, providing additional evidence of rate-limiting $\beta$-hydride elimination at high [(-)-sparteine]; however, these results were initially interpreted in terms of increasing the rate of alkoxide reprotonation. It is also possible that the additive (-)-sparteine $\mathrm{HCl}$ inhibits the alcohol binding equilibrium, with 
Scheme 2. Revised Proposed Mechanism for Oxidation of Alcohols with $\mathrm{Pd}[(-)$-sparteine $] \mathrm{Cl}_{2}$

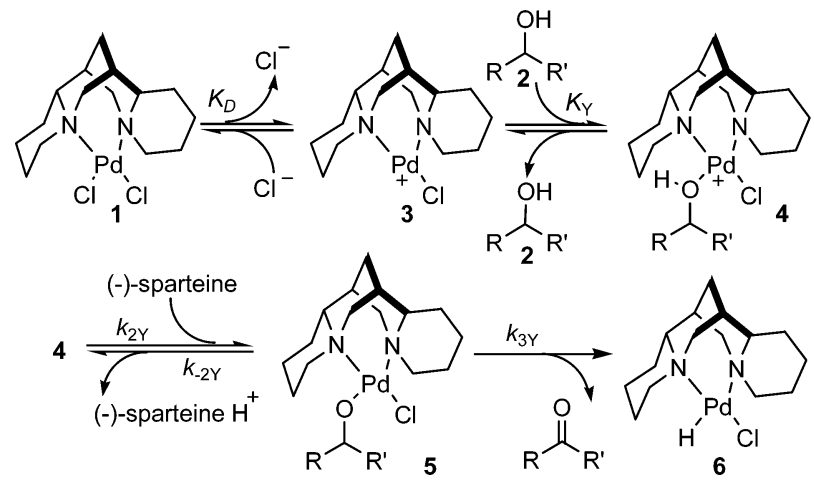

the additional chloride ion driving the back reaction. To test this, we attempted comparable inhibition experiments using several other sources of exogeneous chloride ion, including tetraalkylammonium chlorides and $\mathrm{PPh}_{3}\left(\mathrm{CH}_{2} \mathrm{Ph}\right) \mathrm{Cl}$. The rapid formation of Pd-black or poor solubility of exogenous chloride ion sources made the extraction of kinetic and thermodynamic data from these experiments untenable.

Attempts to monitor alcohol binding and chloride dissociation using conductivity have been more successful. Preparation of the $\mathrm{Pd}[(-)$-sparteine $)] \mathrm{Cl}_{2}$ complex in DCE resulted in a solution with substantial conductivity. Individual solutions of (-)-sparteine and $\mathrm{Pd}\left(\mathrm{NCCH}_{3}\right)_{2} \mathrm{Cl}_{2}$ in DCE showed essentially no conductivity prior to mixing, indicating that $\mathrm{Pd}[(-)$-sparteine $] \mathrm{Cl}_{2}$ exhibits a dissociative pre-equilibrium in the absence of alcohol. Comparison against a calibration curve prepared from $\mathrm{PPh}_{3}\left(\mathrm{CH}_{2}-\right.$ $\mathrm{Ph}) \mathrm{Cl}$ solutions allowed for the determination of the chloride dissociation equilibrium constant $\left(K_{\mathrm{D}}=1.9 \times 10^{-4} \mathrm{M}\right.$, see Supporting Information). Based on the determined value for $K_{\mathrm{D}}$, approximately $35 \%$ of the complex dissociates a chloride under typical OKR reaction conditions ( $1 \mathrm{mM} \mathrm{Pd}[(-)$-sparteine $\left.] \mathrm{Cl}_{2}\right)$.

Addition of up to $0.6 \mathrm{M}$ racemic alcohol caused no increase in conductivity, indicating that alcohol binding does not substantially perturb the dissociative equilibrium. Attempts to study the alcohol binding equilibrium with NMR spectroscopy have also been unsuccessful. Similarly, alcohol dependence studies with up to $0.4 \mathrm{M}$ alcohol show first-order kinetics; saturation in alcohol is not observed under any conditions. On the basis of these results, we conclude that the equilibrium constant for alcohol binding must be significantly smaller than 1 .

Based on these findings, a slightly modified mechanism is proposed for the $\mathrm{Pd}(\mathrm{II})$-catalyzed oxidation of alcohols (Scheme 2). The revised mechanism contains all of the essential features of the original mechanism, with the addition of a rapid preequilibrium for the chloride ion dissociation from the $\operatorname{Pd}[(-)$ sparteine $\mathrm{Cl}_{2}$ complex. The addition of a distinct chloride dissociation step is a relatively minor modification to the original mechanism; further, the modified mechanism is entirely consistent with all of the original kinetic data.

Using the mechanism in Scheme 2 and an enantiomerically pure alcohol substrate, a revised rate law can be derived. Assuming that all steps after $\beta$-hydride elimination are fast, the reaction rate of the $(R)$-enantiomer can be expressed in terms of the $\beta$-hydride elimination step:

$$
v_{R}=k_{3 R}[\mathbf{5}]
$$

The Pd mass balance,

$$
[\mathrm{Pd}]_{\mathrm{t}}=[\mathbf{1}]+[3]+[4]+[5]
$$

can be solved for [5] using the equilibrium constant expressions for the chloride dissociation and alcohol binding equilibria $\left(K_{\mathrm{D}}\right.$ and $K_{\mathrm{R}}$, respectively) and applying the steady-state approximation

$$
0=k_{2 R}[\mathrm{~B}][\mathbf{4}]-k_{3 R}[\mathbf{5}]-k_{-2 R}\left[\mathrm{HB}^{+}\right][\mathbf{5}]
$$

using [5] as the steady-state intermediate. The resulting rate law (full derivation available in Supporting Information) is

$$
\begin{array}{r}
v_{R}=K_{\mathrm{D}} K_{R} k_{2 R} k_{3 R}\left[\mathrm{AH}_{R}\right][\mathrm{B}][\mathrm{Pd}]_{\mathrm{t}} /\left\{\left(K_{\mathrm{D}}+\left[\mathrm{X}^{-}\right]+K_{\mathrm{D}} K_{R}\right.\right. \\
\left.\left.\left[\mathrm{AH}_{R}\right]\right)\left(k_{-2 R}\left[\mathrm{HB}^{+}\right]+k_{3 R}\right)+K_{\mathrm{D}} K_{R} k_{2 R}\left[\mathrm{AH}_{R}\right][\mathrm{B}]\right\}
\end{array}
$$

where $\left[\mathrm{AH}_{\mathrm{R}}\right]$ is $(R)$-sec-phenethyl alcohol, $[\mathrm{B}]$ is $(-)$-sparteine, $[\mathrm{Pd}]_{\mathrm{t}}$ is total $\mathrm{Pd}$ catalyst, $\left[\mathrm{X}^{-}\right]$is chloride ion, and $\left[\mathrm{HB}^{+}\right]$is $(-)$-sparteine $\mathrm{H}^{+}$. Additionally, the alcohol intermediate has been unobservable, even in the presence of large excess of alcohol; hence

$$
K_{\mathrm{R}}\left[\mathrm{AH}_{R}\right] \ll 1
$$

Using this conclusion, the rate law simplifies to

$$
v_{R}=\frac{K_{R} k_{2 R} k_{3 R}\left[\mathrm{AH}_{R}\right][\mathrm{B}][\mathrm{Pd}]_{\mathrm{t}}}{\left(1+\frac{\left[\mathrm{X}^{-}\right]}{K_{\mathrm{D}}}\right)\left(k_{-2 R}\left[\mathrm{HB}^{+}\right]+k_{3 R}\right)+K_{R} k_{2 R}\left[\mathrm{AH}_{R}\right][\mathrm{B}]}
$$

The rate law includes all of the key information supported by the mechanistic studies. The second term in the denominator allows for the observed base saturation behavior. Finally, the revised rate law predicts a complicated inhibition by exogenous $(-)$-sparteine $\mathrm{HCl}$, which impacts both the $\left[\mathrm{X}^{-}\right]$and $\left[\mathrm{HB}^{+}\right]$ terms.

Dependence on Added [(-)-Sparteine $\mathbf{H C l}]$. The derived rate law includes chloride ion $\left[\mathrm{X}^{-}\right]$and sparteine $\mathrm{H}^{+}\left[\mathrm{HB}^{+}\right]$in the denominator, which corresponds to the role of $(-)$-sparteine $\mathrm{HCl}$ as a reaction inhibitor. (-)-Sparteine $\mathrm{HCl}$ can both inhibit the initial dissociative equilibrium and promote reprotonation of the $\mathrm{Pd}-$ alkoxide, rendering a complex rate dependence on $[(-)$-sparteine $\mathrm{HCl}]$. This dependence can be elucidated by examining the rate law with a $1 / v$ plot and assuming that, when excess (-)-sparteine $\mathrm{HCl}$ is added, the concentrations of $\mathrm{HB}^{+}$ and $\mathrm{X}^{-}$are controlled by this amount. In other words, the additional production of $\mathrm{HB}^{+}$and $\mathrm{X}^{-}$from the $\mathrm{Pd}$ starting material's dissociative equilibrium and the deprotonation of the alcohol are negligible relative to the amount intentionally added. This assumption introduces less than a $10 \%$ error in the assumed $\left[\mathrm{X}^{-}\right]$when only 1 equiv of $(-)$-sparteine $\mathrm{HCl}$ is added (relative to $\left[\mathrm{Pd}[(-)\right.$-sparteine $\left.\left.] \mathrm{Cl}_{2}\right]\right)$ at $1 \mathrm{~mol} \%$ in these experiments. Errors in $\left[\mathrm{HB}^{+}\right]$are smaller, and these systematic errors become negligible at higher $[(-)$-sparteine $\mathrm{HCl}]$. This allows for the replacement of both the $\left[\mathrm{HB}^{+}\right]$and $\left[\mathrm{X}^{-}\right]$terms with the concentration of added $(-)$-sparteine $\mathrm{HCl}([\mathrm{SpHCl}])$ in eq 3 :

$$
[\mathrm{SpHCl}]=\left[\mathrm{HB}^{+}\right]=\left[\mathrm{X}^{-}\right]
$$


yielding the rate expression

$$
\frac{v_{R}=}{\frac{K_{R} k_{2 R} k_{3 R}\left[\mathrm{AH}_{R}\right][\mathrm{B}][\mathrm{Pd}]_{\mathrm{t}}}{K_{\mathrm{D}}}[\mathrm{SpHCl}]^{2}+\left(k_{-2 R}+\frac{k_{3 R}}{K_{\mathrm{D}}}\right)[\mathrm{SpHCl}]+k_{3 R}+K_{R} k_{2 R}\left[\mathrm{AH}_{R}\right][\mathrm{B}]}
$$

The concentration of $[(-)$-sparteine $\mathrm{HCl}]$ is then related to $1 / v_{R}$ by the following quadratic equation:

$$
\begin{aligned}
& \frac{1}{v_{R}}=\frac{k_{-2 R}[\mathrm{SpHCl}]^{2}}{K_{\mathrm{D}} K_{R} k_{2 R} k_{3 R}\left[\mathrm{AH} H_{R}\right][\mathrm{B}][\mathrm{Pd}]_{\mathrm{t}}}+\frac{\left(k_{-2 R}+\frac{k_{3 R}}{K_{\mathrm{D}}}\right)[\mathrm{SpHCl}]}{K_{R} k_{2 R} k_{3 R}\left[\mathrm{AH}_{R}\right][\mathrm{B}][\mathrm{Pd}]_{\mathrm{t}}} \\
&+\frac{k_{3 R}+K_{R} k_{2 R}\left[\mathrm{AH} H_{R}\right][\mathrm{B}]}{K_{R} k_{2 R} k_{3 R}\left[\mathrm{AH}_{R}\right][\mathrm{B}][\mathrm{Pd}]_{\mathrm{t}}}
\end{aligned}
$$

This further simplifies to

$$
\begin{aligned}
\frac{[\mathrm{B}][\mathrm{Pd}]_{\mathrm{t}}}{k_{R-\mathrm{obs}}}=\frac{k_{-2 R}[\mathrm{SpHCl}]^{2}}{K_{\mathrm{D}} K_{R} k_{2 R} k_{3 R}}+\frac{\left(k_{-2 R}+\frac{k_{3 R}}{K_{\mathrm{D}}}\right)[\mathrm{SpHCl}]}{K_{R} k_{2 R} k_{3 R}} \\
+\frac{1}{K_{R} k_{2 R}}+\frac{\left[\mathrm{AH}_{R}\right][\mathrm{B}]}{k_{3 R}}
\end{aligned}
$$

Oxidation rates for each enantiomer of sec-phenethyl alcohol were measured under high $(-)$-sparteine conditions (where $\beta$-hydride elimination is rate-limiting) in the presence of added (-)-sparteine $\mathrm{HCl}$ (eq 7). ${ }^{30}$ The data were plotted in the form of quadratic eq 6 . Nonlinear least-squares analysis of each enantiomer yielded excellent fits of the measured data to the quadratic model (Figure 1). The coefficients $A_{\mathrm{Y}}, B_{\mathrm{Y}}$, and $C_{\mathrm{Y}}$ $\left(\mathrm{Y}=R\right.$ or $S$ ) of $f(x)=A_{Y} x^{2}+B_{Y} x+C_{\mathrm{Y}}$ were extracted from the nonlinear least-squares analysis for each alcohol enantiomer (Table 2).

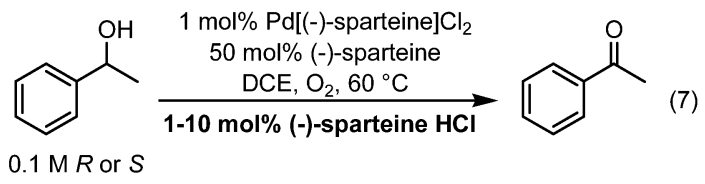

Extraction of Kinetic and Thermodynamic Constants. Thermodynamic and kinetic rate constants $\left(K_{\mathrm{Y}} k_{2 \mathrm{Y}}, k_{3 \mathrm{Y}}, k_{-2 \mathrm{Y}}\right)$ for each enantiomer can be extracted from the quadratic fits to the $[\mathrm{SpHCl}]$ dependence inhibition studies (Table 3 ). The alcohol intermediate has been unobservable and therefore must be present in minute concentrations. Consequently, the alcohol binding and deprotonation steps can only be treated as a single thermodynamic/kinetic event that is described by the combined microscopic constants $K_{\mathrm{Y}} k_{2 \mathrm{Y}}$. Values for $k_{3 \mathrm{Y}}$ can also be determined from previously published [(-)-sparteine] saturation kinetics data using a Lineweaver-Burk plot (see Supporting Information $)$. The values $\left(k_{3 R}=8.7 \times 10^{-2} \mathrm{~min}^{-1}, k_{3 S}=8.5\right.$ $\left.\times 10^{-3} \min ^{-1}, k_{3 R} / k_{3 S}=10\right)$ determined using this method are

(30) The oxidation rate of $(R)$-sec-phenethyl alcohol was measured by monitoring the appearance of acetophenone by in situ IR spectroscopy. Oxidation of (S)-sec-phenethyl alcohol was significantly slower, challenging the limitations of that method of monitoring. Instead, the oxidation rate of the $(S)$ enantiomer was monitored by GC. See Supporting Information for further experimental details
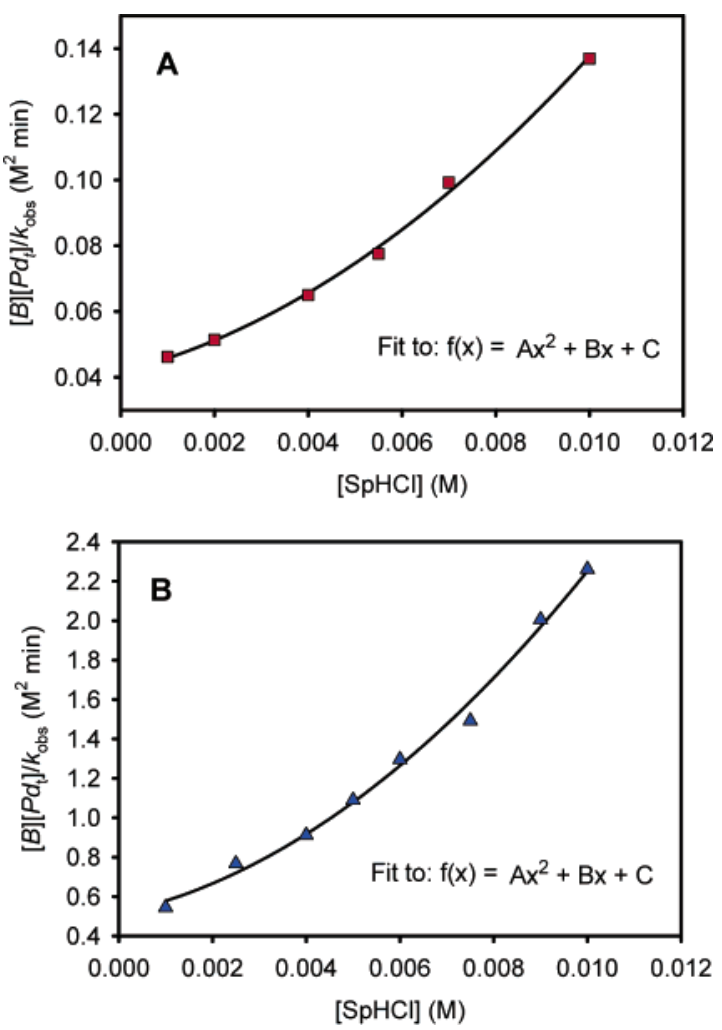

Figure 1. Quadratic fits of alcohol oxidation rate dependence on [ $\mathrm{SpHCl}]$ : (A) (R)-sec-phenethyl alcohol; (B) (S)-sec-phenethyl alcohol.

\begin{tabular}{|c|c|c|c|}
\hline parameters & $(R)$ & $(S)$ & $(R) /(S)$ \\
\hline$K_{\mathrm{Y}} k_{2 \mathrm{Y}}=\frac{1}{K_{\mathrm{D}}\left(B_{\mathrm{Y}}-K_{\mathrm{D}} A_{\mathrm{Y}}\right)}$ & $\begin{array}{l}1500 \pm 500 \\
\mathrm{M}^{-2} \mathrm{~min}^{-1}\end{array}$ & $\begin{array}{l}106 \pm 60 \\
\mathrm{M}^{-2} \min ^{-1}\end{array}$ & 14 \\
\hline$k_{3 \mathrm{Y}}=\frac{\left[\mathrm{AH}_{\mathrm{Y}}\right][\mathrm{B}]}{\left(C_{\mathrm{Y}}-\frac{1}{K_{\mathrm{Y}} k_{2 \mathrm{Y}}}\right)}$ & $\begin{array}{l}0.125 \pm 0.042 \\
\min ^{-1}\end{array}$ & $\begin{array}{l}0.010 \pm 0.006 \\
\min ^{-1}\end{array}$ & 12 \\
\hline$k_{-2 \mathrm{Y}}=A_{\mathrm{Y}} K_{\mathrm{D}} K_{\mathrm{Y}} k_{2 \mathrm{Y}} k_{3 \mathrm{Y}}$ & $\begin{array}{l}21 \pm 10 \\
\mathrm{M}^{-1} \min ^{-1}\end{array}$ & $\begin{array}{l}2.5 \pm 2 \\
\mathrm{M}^{-1} \min ^{-1}\end{array}$ & 8.4 \\
\hline$\frac{k_{-2 Y}}{k_{3 Y}}$ & $\begin{array}{l}170 \pm 98 \\
\mathbf{M}^{-1}\end{array}$ & $\begin{array}{l}240 \pm 250 \\
\mathrm{M}^{-1}\end{array}$ & 0.69 \\
\hline
\end{tabular}

Table 2. Constants from Quadratic Nonlinear Least-Squares Analyses

\begin{tabular}{lccc}
\hline constant & $(R)$ & $(S)$ & equation \\
\hline$A_{\mathrm{Y}}$ & $(6.0 \pm 1.0) \times 10^{2}$ & $(1.2 \pm 0.25) \times 10^{4}$ & $A_{\mathrm{Y}}=\frac{k_{-2 \mathrm{Y}}}{K_{\mathrm{D}} K_{\mathrm{Y}} k_{2 \mathrm{Y}} k_{3 \mathrm{Y}}}$ \\
$B_{\mathrm{Y}}$ & $3.6 \pm 1.2$ & $52 \pm 29$ & $B_{\mathrm{Y}}=\frac{k_{3 \mathrm{Y}}+k_{-2 \mathrm{Y}} K_{\mathrm{D}}}{K_{\mathrm{D}} K_{\mathrm{Y}} k_{2 \mathrm{Y}} k_{3 \mathrm{Y}}}$ \\
$C_{\mathrm{Y}}$ & $0.042 \pm 0.003$ & $0.51 \pm 0.07$ & $C_{\mathrm{Y}}=\frac{k_{3 \mathrm{Y}}+K_{\mathrm{Y}} k_{2 \mathrm{Y}}\left[\mathrm{AH} \mathrm{H}_{\mathrm{Y}}\right][\mathrm{B}]}{K_{\mathrm{Y}} k_{2 \mathrm{Y}} k_{3 \mathrm{Y}}}$ \\
\hline
\end{tabular}

Table 3. Extracted Rate Constants for Pd-Catalyzed sec-Phenethyl Alcohol Oxidation

in reasonable agreement with values determined from the [SpHCl] dependence inhibition studies. Additionally, the Gibbs' free energies of activation were calculated using the values for $k_{3 \mathrm{Y}}$ determined from the [ $\left.\mathrm{SpHCl}\right]$ dependence inhibition studies $\left(\Delta G_{R}=23.7 \pm 0.2 \mathrm{kcal} / \mathrm{mol}\right.$ and $\left.\Delta G_{S}=25.3 \pm 0.3 \mathrm{kcal} / \mathrm{mol}\right)$. These free energy values are in reasonable agreement with those previously measured when no added (-)-sparteine $\mathrm{HCl}$ is used 

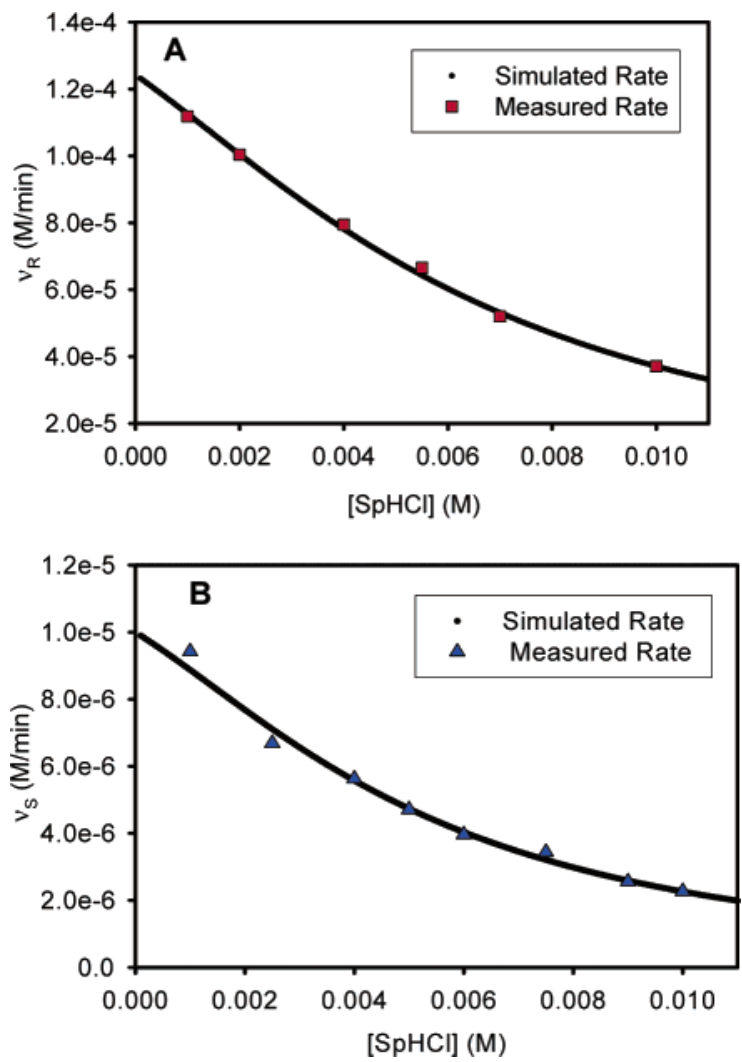

Figure 2. Simulation of (A) (R)-sec-phenethyl alcohol oxidation rates and (B) $(S)$-sec-phenethyl alcohol oxidation rates with additive [SpHCl].

$\left(\Delta G_{R}=22.5 \pm 0.6 \mathrm{kcal} / \mathrm{mol}\right.$ and $\left.\Delta G_{S}=23.8 \pm 2.6 \mathrm{kcal} / \mathrm{mol}\right)$, further supporting that the extracted $k_{3 Y}$ values reflect the experimental events.

Both the $(R)$ and $(S)$ inhibition studies were successfully simulated using the extracted rate constants, the experimental $K_{\mathrm{D}}$, and the rate law associated with the modified mechanism (Figure 2).

Implications of the Intrinsic $\boldsymbol{k}_{\text {rel }}$. The intrinsic $k_{\text {rel }}$ value (the relative observed rate constants for experiments with enantiomerically pure alcohols) can be described by

$$
\begin{aligned}
& k_{\text {rel }}=\left(\frac{K_{R} k_{2 R} k_{3 R}}{K_{S} k_{2 S} k_{3 S}}\right) \times \\
& \left(\frac{\left(K_{\mathrm{D}}+\left[\mathrm{X}^{-}\right]\right)\left(k_{-2 S}[\mathrm{SpHCl}]+k_{3 S}\right)+K_{\mathrm{D}} K_{S} k_{2 S}[\mathrm{~B}]\left[\mathrm{AH}{ }_{S}\right]}{\left(K_{\mathrm{D}}+\left[\mathrm{X}^{-}\right]\right)\left(k_{-2 R}[\mathrm{SpHCl}]+k_{3 R}\right)+K_{\mathrm{D}} K_{R} k_{2 R}[\mathrm{~B}]\left[\mathrm{AH}_{R}\right]}\right)
\end{aligned}
$$

The data clearly show that oxidation of both alcohol enantiomers is inhibited by exogenous (-)-sparteine $\mathrm{HCl}$, but changes in the intrinsic $k_{\text {rel }}$ values are of greater practical importance. An intrinsic $k_{\text {rel }}$ model was generated using eq 8 and the extracted parameters in Table 3. The model indicates that $[(-)$-sparteine $\mathrm{HCl}]$ has a significant effect on the intrinsic $k_{\text {rel }}$. Values for the intrinsic $k_{\text {rel }}$ increase from approximately 12 to 20 over the concentration range studied, corresponding to a relative rate amplification of 1.7 (Figure 3).

Oxidative Kinetic Resolution in the Presence of Exogenous (-)-Sparteine HCl. Under high [(-)-sparteine] conditions, a significant difference between measured intrinsic $k_{\text {rel }}$ values (ca. 11) and racemate $k_{\text {rel }}$ values (ca. 25) is observed. The individual steps in the reaction mechanism for the racemate are assumed

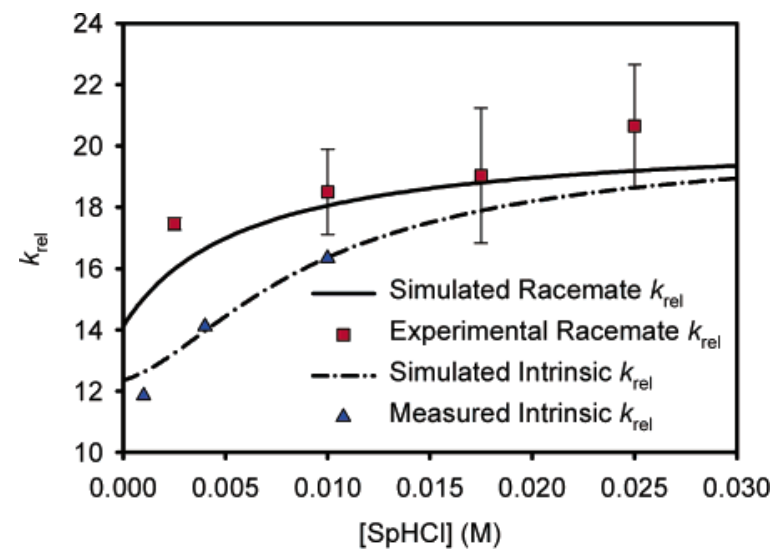

Figure 3. Simulated OKR $k_{\text {rel }}$ values using enantioselective model in eq 11.

Scheme 3. Mechanism of Pd-Catalyzed OKR of sec-Phenethyl Alcohol
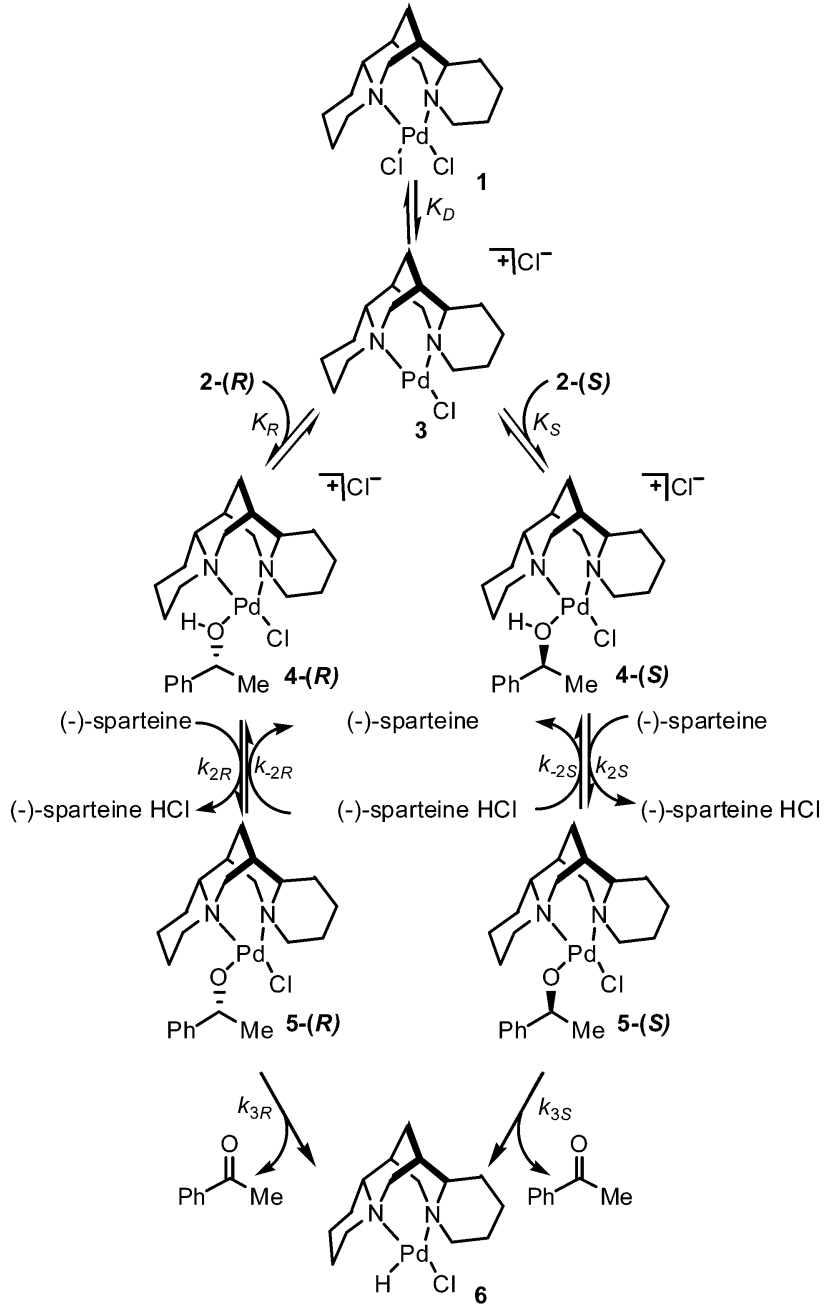

to be the same as with the single enantiomers; however, an important distinction must be included. The racemate rate law must also describe the competition between alcohol enantiomers for a single chiral Pd catalyst. Even though the individual mechanistic steps remain unchanged, this competition substantially complicates the reaction network and the rate law (Scheme 3).

The derivation of the racemate rate law is qualitatively similar to the single enantiomer rate law derivation, with the exception 
of a more complicated Pd mass balance. Assuming that all steps after $\beta$-hydride elimination are fast, the reaction rates can be expressed in terms of the $\beta$-hydride elimination step:

$$
v_{R}=k_{3 R}[\mathbf{5}-(\boldsymbol{R})]
$$

The Pd mass balance,

$$
[\mathrm{Pd}]_{\mathrm{t}}=[\mathbf{5}-(\boldsymbol{R})]+[\mathbf{4}-(\boldsymbol{R})]+[\mathbf{1}]+[\mathbf{3}]+[\mathbf{4 -}(\boldsymbol{S})]+[\mathbf{5 -}(\mathbf{S})]
$$

can be solved for $[\mathbf{5}-(\boldsymbol{R})]$ in the same fashion as for the single enantiomer experiments, assuming that the chloride dissociation and alcohol binding equilibria are fast (established) preequilibria. Because both reactions occur simultaneously, both $[\mathbf{5}-(\boldsymbol{R})]$ and $[\mathbf{5}-(\boldsymbol{S})]$ must be treated as steady-state intermediates, described by the equations

$$
0=k_{2 R}[\mathbf{4}-(\boldsymbol{R})][\mathrm{B}]-k_{3 R}[\mathbf{5}-(\boldsymbol{R})]-k_{-2 R}\left[\mathrm{HB}^{+}\right][\mathbf{5}-(\boldsymbol{R})]
$$

or

$$
0=k_{2 R}[\mathbf{4}-(\boldsymbol{R})][\mathrm{B}]-k_{3 R^{*}}[\mathbf{5}-(\boldsymbol{R})]
$$

where $k_{3 R^{*}}=\left(k_{3 R}+k_{-2 R}\left[\mathrm{HB}^{+}\right]\right.$and

$$
0=k_{2 S}[\mathbf{4}-(\mathbf{S})][\mathrm{B}]-k_{3 S^{*}}[\mathbf{5}-(\boldsymbol{S})]
$$

where $k_{3 S^{*}}=\left(k_{3 S}+k_{-2 S}\left[\mathrm{HB}^{+}\right]\right)$. Using these assumptions and that $K_{\mathrm{Y}}$ is significantly less than 1 , the following rate laws were derived (see Supporting Information):

$$
\frac{v_{R}=}{K_{\mathrm{D}} K_{R} k_{2 R} k_{2 R} k_{3 R}\left[\mathrm{AH}_{R}\right][\mathrm{B}]+k_{3 R^{*}}\left[\left[\mathrm{X}^{-}\right]+K_{\mathrm{D}}+K_{\mathrm{D}} K_{S}\left[\mathrm{AH}_{S}\right]\left(\frac{k_{2 S}[\mathrm{~B}]}{k_{3 S^{*}}}\right)\right]}
$$

$$
\begin{aligned}
& v_{S}= \\
& \frac{K_{\mathrm{D}} K_{S} k_{2 S} k_{3 S}\left[\mathrm{AH}_{S}\right][\mathrm{B}][\mathrm{Pd}]_{\mathrm{t}}}{K_{\mathrm{D}} K_{S} k_{2 S}\left[\mathrm{AH}_{S}\right][\mathrm{B}]+k_{3 S^{*}}\left[\left[\mathrm{X}^{-}\right]+K_{\mathrm{D}}+K_{\mathrm{D}} K_{R}\left[\mathrm{AH}_{R}\right]\left(\frac{k_{2 R}[\mathrm{~B}]}{k_{3 R^{*}}}\right)\right]}
\end{aligned}
$$

An important consequence of this rate law is that the rate of alcohol oxidation for each enantiomer now depends on the oxidation rate for the other, reflecting the competition for the Pd catalyst. ${ }^{34,35}$

The overall $k_{\text {rel }}$ value can be expressed by

$$
\begin{aligned}
& k_{\mathrm{rel}}=\left(\frac{K_{R} k_{2 R} k_{3 R}}{K_{S} k_{2 S} k_{3 S}}\right) \times \\
& \left(\left[K_{\mathrm{D}} K_{S} k_{2 S}\left[\mathrm{AH}_{S}\right][\mathrm{B}]+k_{3 S^{*}}\left(\left[\mathrm{X}^{-}\right]+K_{\mathrm{D}}+\frac{K_{\mathrm{D}} K_{R} k_{2 R}\left[\mathrm{AH}_{R}\right][\mathrm{B}]}{k_{3 R^{*}}}\right)\right]\right. \\
& {\left[\left[K_{\mathrm{D}} K_{R} k_{2 R}\left[\mathrm{AH}_{R}\right][\mathrm{B}]+k_{3 R^{*}}\left(\left[\mathrm{X}^{-}\right]+K_{\mathrm{D}}+\frac{K_{\mathrm{D}} K_{S} k_{2 S}\left[\mathrm{AH}_{S}\right][\mathrm{B}]}{k_{3 S^{*}}}\right)\right]\right.}
\end{aligned}
$$

To test this enantioselective model, racemate $k_{\text {rel }}$ values were measured with additive (-)-sparteine $\mathrm{HCl}$ (eq 12). ${ }^{31}$ The model successfully predicts the $k_{\text {rel }}$ values of OKR of racemic secphenethyl alcohol (Figure 3).

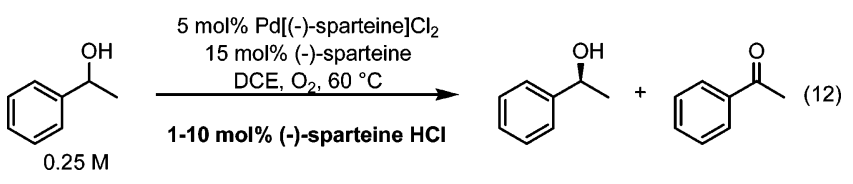

Origin of Enantioselectivity. Of fundamental importance is the origin of enantioselectivity for the system, particularly the enantioselectivity enhancement observed using the racemate. The original proposal for the Pd-catalyzed aerobic oxidation of chiral alcohols was that enantioselectivity at high [(-)-sparteine] was due to a combination of kinetic differences in $\beta$-hydride elimination and a thermodynamic difference in $\mathrm{Pd}-$ alkoxide stabilities favoring the $(R)$-enantiomer of alcohol. This proposal does not explain our present observations. The current investigations indicate that relative thermodynamics play an unclear role and that enantiodifferentiation in this system arises largely from reactivity differences and the details of the reaction kinetics.

Both thermodynamic and kinetic factors can affect selectivity in a catalytic system, although they do not necessarily work in concert. In a seminal report on enantioselective hydrogenation by $\mathrm{Rh}$ (diphos) complexes, Halpern described kinetic and thermodynamic limiting scenarios in determining enantioselectivity for asymmetric catalytic systems: (1) the prevailing reactive species is determined by the initial substrate binding event, and (2) the prevailing reactive species arises from the minor catalyst-substrate diastereomer by virtue of its much higher reactivity. ${ }^{32}$ In this study, Halpern and co-workers found that the thermodynamic stability of intermediates is of secondary importance to their intrinsic reactivity. Specifically, the minor diastereomeric species undergoes a far more facile addition of hydrogen than the major diastereomer, illustrating a selective process that is purely kinetically controlled. This is an elegant proof that the Curtin-Hammett principle must be considered when dealing with selectivity in catalytic systems. Simply stated, the Curtin-Hammett principle asserts that one cannot draw a causal relationship between product ratios and the relative proportions of intermediates in a fast equilibrium. ${ }^{33}$

(a) Thermodynamic Influences. The small alcohol binding constants make evaluation of thermodynamic influences in this system difficult, at best. We have been unable to observe alcohol binding to the $\mathrm{Pd}$ center and have treated this binding as a fast, established pre-equilibrium. Consequently, it is not possible to differentiate between thermodynamic and kinetic factors in the relative binding rates of $(R)$ - and $(S)$-sec-phenethyl alcohols. Using the presently available data, it is only possible to point out that the combination of binding constants $\left(K_{\mathrm{Y}}\right)$ and deprotonation rate constants $\left(k_{2 Y}\right)$ results in an approximately 10fold greater net reactivity for $(R)$-sec-phenethyl alcohol.

For the OKR reaction, the magnitude of the $k_{-2} / k_{3}$ ratios $((R)$ $=170 \mathrm{M}^{-1},(S)=240 \mathrm{M}^{-1}$, Table 3) suggests that the reprotonation reactions are facile and the system may approach

(31) The $k_{\text {rel }}$ was calculated using $k_{\text {rel }}=\ln [(1-C)(1-$ ee $)] / \ln [(1-C)(1+$ ee)], where $C$ is the conversion and ee is the enantiomeric excess, see: Kagan, H. B.; Fiaud, J. C. Kinetic Resolution. Top. Stereochem. 1988, 18, 249-329.

(32) Halpern, J. Science 1982, 217, 401-407.

(33) Curtin, D. Y. Rec. Chem. Prog. 1954, 15, 111. 
equilibrium. However, since the magnitude of $k_{2 Y}$ (the deprotonation rate constant) cannot readily be determined, it is also possible that the two parallel intermediates never establish a true thermodynamic equilibrium. For clarification, we define this thermodynamic equilibrium specifically as the ratio of $\mathrm{Pd}-$ alkoxide intermediates that is governed by their free energies of formation. The kinetic steady state, on the other hand, requires only that the concentrations of intermediates remain constant over time; it does not imply that those concentrations are equivalent to expected concentrations based on thermodynamic equilibria or the relative stabilities of the two Pd-alkoxides. It is then possible that relative stabilities may play little or no role in determining the product ratios in the catalytic system. Consequently, for the OKR reaction, the influence of relative $\mathrm{Pd}$-alkoxide stabilities is not at all clear, not readily determinable, and may even have little consequence for the origin of the enantioselectivity.

(b) Kinetic Influences. The kinetic evidence indicates that each of the mechanistic steps favors $(R)$-alcohol oxidation. The primary adjustable parameters in this reaction are $[(-)$-sparteine] and $\left[\mathrm{HB}^{+}\right]$; increasing the concentration of either reagent enhances enantioselectivity in this system. For comparison purposes, the "baseline" selectivity for this system is the intrinsic selectivity under low [(-)-sparteine] conditions, where alcohol deprotonation is rate determining and enantioselectivity is set by the relative rates of deprotonation. The intrinsic $k_{\text {rel }}$ measured under these conditions shows deprotonation of the $(R)$-enantiomer to be favored by a factor of 6 (Table 1). The determined value of $K_{R} k_{2 R} / K_{S} k_{2 S}$ (14, Table 3 ) is consistent with this observation (the ratio of the microscopic constants is larger than the measured $k_{\text {rel }}$ because $k_{\text {obs }}$ values also include several terms in the denominators).

Subsequent mechanistic steps serve to enhance this baseline selectivity. At higher [(-)-sparteine], the intrinsic $k_{\text {rel }}(11$, Table 1) nearly doubles as the rate-determining step moves from Pdbound alcohol deprotonation to $\mathrm{Pd}$-alkoxide $\beta$-hydride elimination. With this change in rate-limiting step, determined $\beta$-hydride elimination rate constants $\left(k_{3}\right.$, Table 3$)$ also show an approximate factor of 10 difference between the $(R)$ - and $(S)$-alkoxides. This enhancement must be independent of the relative alkoxide thermodynamic stabilities, as those terms can appear only in steps leading up to alcohol deprotonation. Consequently, the $\beta$-hydride elimination enhancement is purely kinetic in nature, reflecting a greater reactivity of the $(R)$-bound alkoxide.

Although the reprotonation reaction was proposed in the original mechanism, this step appears to be far more important than we initially realized, as experimentally determined intrinsic $k_{\text {rel }}$ values increase substantially with added (-)-sparteine $\mathrm{HCl}$, approaching 20 (Figure 3). For both bound alkoxides, the determined values for $k_{-2}$ are 2 orders of magnitude greater than $k_{3}$. Further, the $k_{-2} / k_{3}$ values $((R) /(S)=0.69$, Table 3$)$ are also the only kinetic terms that are larger for the $(S)$ - than for the $(R)$-enantiomer. The net result is that, for this system, even the reprotonation reaction works in concert with the other kinetic steps to favor oxidation of the $(R)$-alkoxide. Additionally, it is clear that reprotonation plays a critical role in determining the concentration of $\mathrm{Pd}$-alkoxide at high [(-)-sparteine], and likely has an important role even when the added [(-)-sparteine] is low.
Enantioselectivity Enhancement in Racemate Experiments. The increased enantiodifferentiation (relative to the single enantiomer experiments) observed upon oxidation of the racemate can only be reasonably attributed to kinetic effects. In examining this assertion, the possibility that the mechanism changes for the racemate must be considered. Along those lines, it is possible that, for the racemate, the diastereomers interact in some manner to change the intrinsic stabilities and/or reactivities of the intermediates. Given the extremely low concentrations of the active species and the quality of the fit to the experimental data in Figure 3, these possibilities are unlikely to be of consequence.

Rather, two key properties unique to the oxidative kinetic resolution appear to be at work. First, the racemate experiments contain an inherent competition between the alcohols for the catalytically active Pd species. This competition is not present in single enantiomer experiments, and this explanation relies only on the clear experimental evidence that the $\mathrm{Pd}-(R)$ alkoxide is produced at a faster rate than the $\mathrm{Pd}-(S)$-alkoxide. When the two alcohols are in competition for the catalyst, this kinetic enhancement can be thought of as "pulling" the equilibrium farther toward the $(R)$ reaction network, partially starving the $(S)$ network. ${ }^{34,35}$ It is difficult to quantify the importance of this competition; however, its direct impact on the increased enantioselectivity in racemate experiments is likely to be small. The relatively large value for chloride dissociation and small values for alcohol binding imply that a large excess of the monochloro-Pd species $\mathbf{3}$ is available; hence, the individual alcohol binding equilibria (and subsequent deprotonation and oxidation) are unlikely to substantially impact one another.

The second property of this competition is more subtle, but appears to drive the higher selectivities observed in racemate over single enantiomer experiments. The assumption that rate constants remain the same from the single enantiomer to racemate conditions (vida supra) does not imply that intermediate concentrations remain constant. Hence, the absolute rates of individual steps, which depend on both intermediate concentrations and rate constants, are not necessarily identical in both experiments. In the $\mathrm{OKR}$ reaction, $\left[\mathrm{HB}^{+}\right]$appears to be the key intermediate in explaining the observed enantiodifferentiation enhancement in racemate experiments, which result from a suppression of the $(S)$-enantiomer pathway and an effective increase in $k_{\text {rel }}$.

In single enantiomer experiments, the $\mathrm{Pd}-(R)$-alkoxide is produced roughly an order of magnitude faster than the $\mathrm{Pd}-$ $(S)$-alkoxide $\left(K_{R} k_{2 R} / K_{S} k_{2 S}=14\right.$, Table 3$)$. Because these steps in the reaction produce one equivalent of $\mathrm{HB}^{+}$, it is reasonable to conclude that, once steady state is established, the $\left[\mathrm{HB}^{+}\right]$in the $(R)$ single enantiomer experiments is approximately an order of magnitude greater than the $\left[\mathrm{HB}^{+}\right]$in the $(S)$ single enantiomer experiments. However, a single steady state is established in experiments with the racemate. Since the oxidation of the $(R)$ alcohol is the dominant pathway, the $\left[\mathrm{HB}^{+}\right]$in racemate experiments will be largely determined by $(R)$-alcohol oxidation kinetics. For the $(S)$-enantiomer pathway in OKR, this results in a roughly 10 -fold increase in $\left[\mathrm{HB}^{+}\right]$relative to the single enantiomer experiment. This increase in $\left[\mathrm{HB}^{+}\right]$drives the $(S)$ -

(34) Blackmond, D. G. J. Am. Chem. Soc. 2001, 123, 545-553. (35) Andraos, J. J. Phys. Chem. A 2003, 107, 2374-2387. 
alkoxide reprotonation reaction faster in OKR than in the $(S)$ single enantiomer experiment, resulting in the net slowing of the $(S)$ pathway and an observed increase in $k_{\text {rel }}$ for the racemate.

This explanation is strongly supported by the kinetic models and the (-)-sparteine $\mathrm{HCl}$ inhibition studies. As greater amounts of exogenous (-)-sparteine $\mathrm{HCl}$ are added to the reaction, the catalytic cycle's contribution to the overall $\left[\mathrm{HB}^{+}\right]$diminishes. Once the catalytic cycle's contribution becomes negligible, the exogenous (-)-sparteine $\mathrm{HCl}$ sets the $\left[\mathrm{HB}^{+}\right]$in both the single enantiomer and racemate experiments, and there should be little difference between the intrinsic and racemate $k_{\text {rel }}$ values. As shown in Figure 3, the differences between intrinsic and racemate $k_{\text {rel }}$ values rapidly diminish with added (-)-sparteine $\mathrm{HCl}$, and the two curves approach a common $k_{\text {rel }}$ of approximately 20 , in good agreement with the experimental data. The close approach of these two curves also supports the conclusion that competition for the catalyst plays only a minor role in the increased enantiodifferentiation during racemate experiments.

Relevance to Other Models and Systems. The kinetic enantioselective model is a good complement to the current structural $^{28}$ and computational ${ }^{29}$ models. These studies have provided a detailed, albeit complex mathematical picture of how each component of the reaction interacts with the others to define the overall enantioselectivity between alcohols. An important question arises when considering the role of reprotonation in enhancement of enantioselectivity in Pd-catalyzed aerobic OKR of sec-phenethyl alcohol. This is true whether the relative difference in reprotonation is due to the diastereomeric interactions of a bulky chiral acid and a bulky chiral $\mathrm{Pd}$-alkoxide species or due to the inherent ease of reprotonation of one diastereomer of $\mathrm{Pd}-$ alkoxide over the other, regardless of the nature of the acid. If it is the latter, this would imply that an achiral base/acid system could be used with $\operatorname{Pd}[(-)$ sparteine]$\mathrm{Cl}_{2}$ catalyst for OKR of alcohols. In fact, several achiral bases have been shown to give good selectivities in Pd-catalyzed aerobic OKR, with carbonates in $t \mathrm{BuOH}$ being some of the best. ${ }^{36,37}$

There are several limitations to the insights our studies provide. The chloride ions on $\mathrm{Pd}[(-)$-sparteine $] \mathrm{Cl}_{2}$ are diastereotopic; therefore, two separate alkoxides can be formed from each enantiomer of alcohol. Thus, the extracted kinetic constants are combinations of the two possible intermediates for each enantiomer of alcohol at each step. These two possible diastereomeric forms of alkoxides for each enantiomer of alcohol are kinetically indistinguishable. The kinetic models provide no further insight into the active species or the origin of the "baseline" preference for oxidation of the $(R)$-enantiomer of the alcohol; hence, we cannot comment on structural aspects of the model. In contrast, the solid-state structural ${ }^{28}$ and computational ${ }^{29}$ models have addressed the possibility of four diaster-

(36) Mandal, S. K.; Sigman, M. S. J. Org. Chem. 2003, 68, 7535-7537.

(37) Bagdanoff, J. T.; Ferreira, E. M.; Stoltz, B. M. Org. Lett. 2003, 5, 835837. eomeric alkoxides being formed, depending on which chloride dissociates from the original $\operatorname{Pd}[(-)$-sparteine $] \mathrm{Cl}_{2}$. A good pictorial model is proposed of three-dimensional interactions that induce enantiodifferentiation during $\beta$-hydride elimination. However, to achieve this, the experimental conditions under which OKR occurs were avoided and could not be simulated computationally.

On many levels our kinetic model is consistent with that put forth by Nielsen and co-workers. ${ }^{29}$ Both models agree that the kinetic contribution of $\beta$-hydride elimination is significant. However, our model differs from the computational model of Nielsen and co-workers in that they arrive at the conclusion that the enantioselectivity is exclusively limited to $\beta$-hydride elimination. This could be due to the incomplete representation of all the steps involved due to computational limitations. Our kinetic studies complement their computational studies, as we were able to gain insight into the deprotonation/reprotonation steps that eluded calculation.

\section{Conclusion}

A mathematical model for the enantioselective oxidation of chiral alcohols using $\operatorname{Pd}[(-)$-sparteine $] \mathrm{Cl}_{2}$ has been elucidated. It successfully predicts experimental $k_{\text {rel }}$ values where the concentration of (-)-sparteine $\mathrm{H}^{+}$can be approximated. Enantioselection during Pd-catalyzed OKR is a complex combination of thermodynamic and kinetic events. It can be summarized as a competition between enantiomers of alcohol for an active Pd catalyst and a balance of kinetic $\beta$-hydride elimination and reprotonation by (-)-sparteine $\mathrm{HCl}$. The model predicts changes of experimental $k_{\text {rel }}$ values compared to intrinsic $k_{\text {rel }}$ values at various [(-)-sparteine $\mathrm{HCl}]$. Additionally, $k_{\mathrm{rel}}$ improvement is possible through the addition of (-)-sparteine $\mathrm{HCl}$. Using this information, we plan to design and evaluate bifunctional catalysts for the palladium-catalyzed oxidative kinetic resolution of alcohols.

Acknowledgment. The genesis of this study arose from a senior-level undergraduate interdisciplinary course co-taught by B.D.C. and Dr. Nancy Mills at Trinity University. We very gratefully thank Dr. Mills for her contributions to this study and the students enrolled in the course for their discussions. B.D.C. and A.C. gratefully acknowledge the Research Corporation (Grant No. W-1552) for financial support of this work. M.S.S. thanks the National Institutes of Health (NIGMS No. RO1 GM63540) and the Dreyfus Foundation (Teacher Scholar Award) for financial support. J.A.M. thanks the American Association of University Women Educational Foundation for a 2004-2005 American Fellowship.

Supporting Information Available: Experimental procedures, graphs, data tables for the kinetic study, and rate law derivations. This material is available free of charge via the Internet at http://pubs.acs.org.

JA053195P 